\title{
Duration-dependent Effects of the Bite-raised Condition on Hippocampal Function in SAMP8 Mice
}

\author{
By
Yoko ARAKAWA ${ }^{1}$, Yukiko ICHIHASHI ${ }^{1}$, Mitsuo IINUMA ${ }^{1}$, Yasuo TAMURA ${ }^{1}$, Fumihiko IWAKU ${ }^{2}$ and Kin-ya KUBO ${ }^{2}$ \\ ${ }^{1}$ Departments of Pediatric Dentistry, 1851-1 Hozumi, Mizuho, Gifu, 501-0296, Japan \\ ${ }^{2}$ Oral Anatomy, Asahi University School of Dentistry, 1851-1 Hozumi, Mizuho, Gifu, 501-0296, Japan
}

- Received for Publication, September 21, 2007-

Key Words: Occlusal disharmony, Hippocampus, Spatial memory, Neuron number, SAMP8 mice

\begin{abstract}
Summary: We evaluated the effect of the duration of occlusal disharmony induced chronic stress on hippocampal function by examining spatial memory in the Morris water maze and on the number of hippocampal neurons in aged senescence-accelerated prone (SAMP8) mice. The bite of SAMP8 mice was raised $0.1 \mathrm{~mm}$ using dental adhesive. Groups of mice were tested in the Morris water maze 8, 11, or $22 \mathrm{~d}$ after raising the bite. The results indicated that the longer the duration of the bite-raised condition, the greater the impairment in spatial learning ability and the greater the decrease in the number of neurons in the hippocampal CA3 subfield. Thus, behavioral and morphologic deficits induced by the bite-raised condition in aged SAMP8 mice are influenced by the duration of the occlusal disharmony.
\end{abstract}

Occlusal disharmony is currently a topic of great interest, due to clinical reports of patients with general malaise that greatly improved after treatment of occlusal disharmony ${ }^{1,2}$. In humans, occlusal interference influences electroencephalographic findings ${ }^{3,4)}$. In rats, the application of incisal caps increases plasma corticosterone levels ${ }^{5)}$ and modulates central catecholaminergic activity $^{6}$. In our recent studies using aged accelerated senescence-prone mice (SAMP8), the bite-raised condition induced impairments of spatial learning in the Morris water maze and increased plasma corticosterone levels and neuronal death in the hippocampal CA3 subfield ${ }^{7)}$. Injection of metyrapone, a corticosterone synthesis blocker ${ }^{8)}$, prevents the bite-raised condition-induced hippocampal neuron loss and spatial memory deficits ${ }^{9}$. These data suggest that chronic stress is involved in the occlusal disharmony-induced hippocampaldependent pathologic changes.

The effects of chronic stress are duration dependent $^{10,11)}$, e.g., molarless condition-induced spatial learning deficits and neuron loss increase as the duration of the molarless condition increases ${ }^{10)}$. It is not known, however, whether the duration of the bite-raised condition influences the behavioral and morphologic changes induced by the bite-raised condition. In the present study, we examined the effects of duration of the bite-raised condition on hippocampal neuron number and cognitive performance in the water maze.

\section{Materials and Methods}

Male SAMP8 mice $(9$-mo-old, $\mathrm{n}=30)$ were used in this study. The features of this strain are described in detail elsewhere ${ }^{12,13)}$. The animals were treated in accordance with the principles approved by the Council of the Japanese Neuroscience Society. The mice were bred and maintained under conventional conditions and housed in groups of five in plastic cages under temperature- and humiditycontrolled conditions $\left(23 \pm 1^{\circ} \mathrm{C}, 55 \pm 2 \%\right)$ on a 12-h light cycle with free access to food and water.

The mice were anesthetized with sodium pento-

All correspondence should be addressed to: Mitsuo Iinuma, Department of Pediatric Dentistry, Division of Oral Structure, Function and Development, Asahi University School of Dentistry, 1851 Hozumi, Mizuho, Gifu, 501-0296, Japan. E-mail: iinuma@dent.asahi-u .ac.jp 
barbital (35 mg/kg body weight) and the vertical dimension of the bite was raised as previously described $^{7)}$. Briefly, the vertical dimension was raised by placing ultraviolet-ray polymerization resin (UniFilßLoFlo, GC Corporation, Tokyo, Japan) on the upper molars (maxillary molars) after treatment with the Single Bond Dental Adhesive System (3M Dental Product Products, St. Paul, MN). The increase in the vertical occlusal dimension was approximately $0.1 \mathrm{~mm}$. Control animals underwent the same surgical procedure except that the resin was not placed on their upper molars. After the operation, the mice were allowed free access to pelleted chow and water. There were six groups of mice $(\mathrm{n}=5$ each), three control and three biteraised, that were tested in the Morris water maze beginning either $8 \mathrm{~d}, 15 \mathrm{~d}$, or $22 \mathrm{~d}$ after surgery (one control group and one bite-raised group at each time point).

The Morris water maze test is a sensitive assay for hippocampal abnormalities ${ }^{14,15}$. The Morris water maze learning test was performed as previously described ${ }^{5)}$, beginning $8 \mathrm{~d}, 15 \mathrm{~d}$, and $22 \mathrm{~d}$ after surgery. Briefly, a stainless steel tank $(90 \mathrm{~cm}$ in diameter, $30 \mathrm{~cm}$ deep), was filled with water (about $28^{\circ} \mathrm{C}$ ) to a height of $22 \mathrm{~cm}$ and the water surface was covered with floating polystyrene foam granules (approximately $2 \mathrm{~mm}$ in diameter). A platform was submerged $1 \mathrm{~cm}$ under the water surface and located at a constant position near the center of one of the four quadrants of the pool. At $8 \mathrm{~d}, 15 \mathrm{~d}$, or $22 \mathrm{~d}$ after surgery, the mice were placed into the water from one of four points around the perimeter of the tank and given 28 trials over 7 consecutive days ( 4 trials per day). The sequence of starting positions was changed randomly every day. The swim paths, distances, and latencies to reach the platform were monitored using a CCD video camera linked to a computer system (Movetr/2D, Library Co., Ltd, Tokyo, Japan).

We also counted the number of neurons in the CA3 subfield of the hippocampus in these animals; the bite-raised condition-induced neuron loss occurs only in the hippocampal CA3 subfield ${ }^{7}$. On the final training day (day 7), five mice of each group were anesthetized with pentobarbital sodium $(40 \mathrm{mg} / \mathrm{kg})$ and perfused transcardially with $30 \mathrm{ml}$ of saline at $37^{\circ} \mathrm{C}$, followed by $100 \mathrm{ml}$ of neutral buffered formalin. The brain was carefully removed and post-fixed in the same fixative for over night. Serial sections $(15 \mu \mathrm{m})$ were cut and mounted, then stained with Cresyl Violet.

Quantitative analysis of pyramidal cells was performed as described previously ${ }^{7,16}$. Round, clear, medium, and large cells were counted in the left dorsal hippocampus (Bregma: $-2.46 \mathrm{~mm}$ using the atlas of Franklin and Paxinos ${ }^{17)}$ ) on two sections per animal using a $20 \times$ microscope objective. For each section, all cells meeting the criteria described above were counted in the hippocampal pyramidal layer along a $140-\mu \mathrm{m}$ long line (the diagonal of a $100 \times 100 \mu \mathrm{m}$ square) in three distinct zones of the CA3 region. The data from each zone were pooled and the mean value for the CA3 region was estimated and expressed in terms of cell number per square millimeter.

Analysis of variance followed by Fisher's PLSD analysis was used to evaluate the statistical significance of behavioral and morphologic differences between the control and bite-raised groups.

\section{Results}

We examined the effect of the bite-raised condition on spatial cognitive performance in the Morris water maze at different intervals $(8,15,22 \mathrm{~d})$ after performing the procedure to raise the bite. The latency to reach the platform was significantly greater in mice in the bite-raised condition compared to controls $[F(5,144)=7.066, P=0.0003]$. The longer the duration of the bite-raised condition, the greater the latency to reach the platform, and there

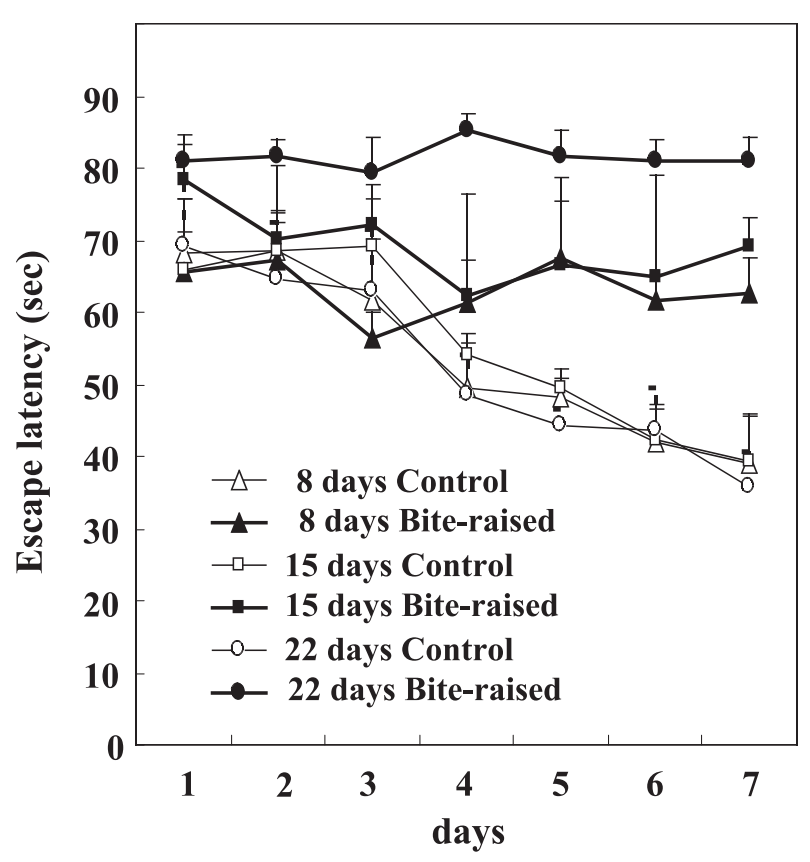

Fig. 1. Spatial learning in the water maze test. The results are expressed as the mean score (mean $\pm \mathrm{SE}, \mathrm{n}=5$ for each group) of four trials per day. Note that the bite-raised mice required a significantly longer time to reach the platform than did control mice. 


\section{8 days}
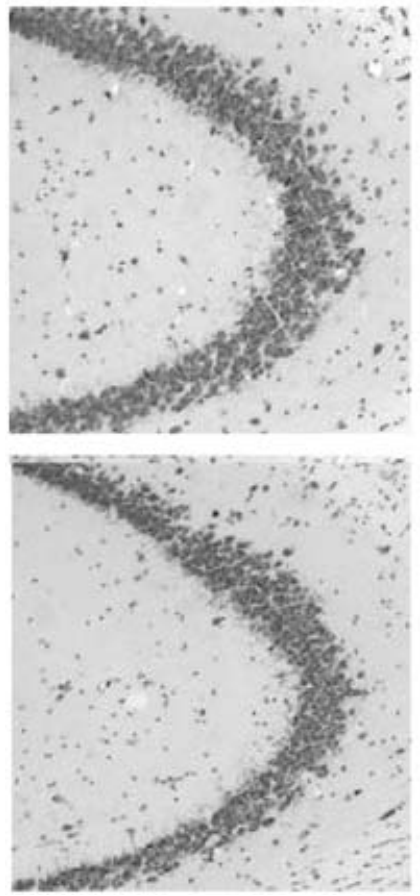

15 days
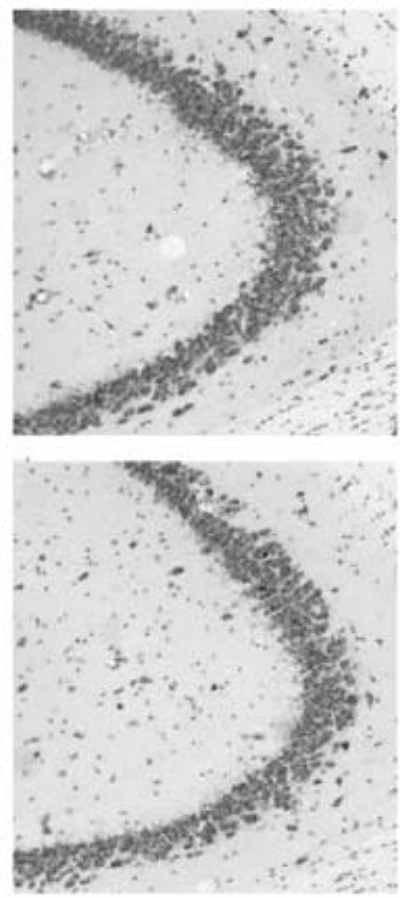

22 days
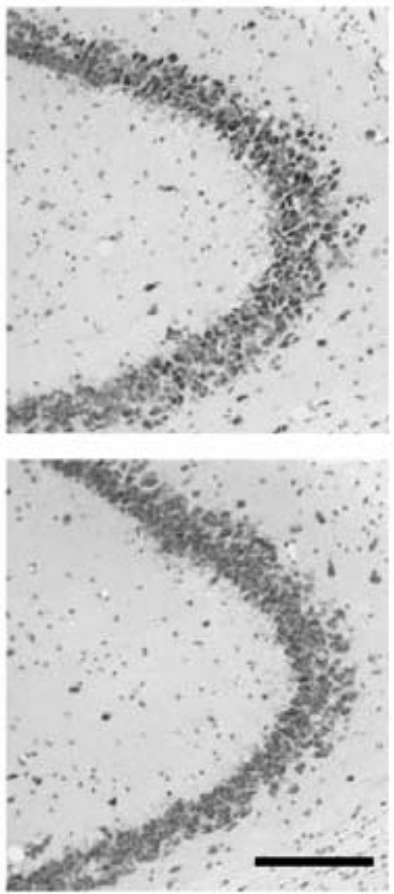

Fig. 2. Photomicrographs showing Nissl staining of hippocampal CA3 subfield. Bars: $200 \mu \mathrm{m}$. Note that there were fewer pyramidal cells in the $\mathrm{C} 3$ region of the bite-raised mice than in control mice.

was a significant difference between 8 days and 22 days after the operation $(P=0.0052)$.

Quantitative analysis of cell numbers also showed that the density of pyramidal cells in the CA3 region of bite-raised mice was significantly decreased 8 days after the operation compared with control mice (Fig. 3, $P<0.0001$ ) and continued to decrease as the duration the condition increased. There was a significant difference between the 8-d and $15-\mathrm{d}$ groups $(P<0.0001)$ and between the $15-\mathrm{d}$ and 22-d groups $(P=0.0054)$. This change was not observed in control mice, indicating a relationship between the duration of the bite-raised condition and the decrease in both learning ability and pyramidal cell density in the CA3 region.

\section{Discussion}

The present findings, based on both behavioral and morphologic techniques, provides support that the bite-raised condition-induced behavioral and morphologic deficits in SAMP8 mice depend on the duration of the bite-raised condition. These data are consistent with those in previous reports that an increase in the duration of the molarless condi-

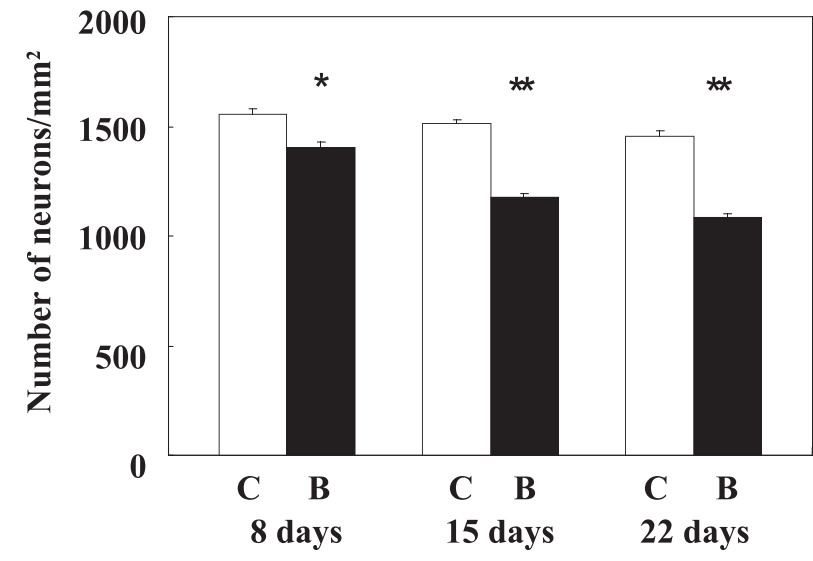

Fig. 3. Effect of the bite-raised condition on neuronal number in the hippocampal CA3 subfield. The results are expressed as the mean number of neurons/mm squared (mean $\pm \mathrm{SE}, \mathrm{n}=5$ for each group). C: Control mice; $\mathrm{B}$ : Bite-raised mice. ${ }^{* *}: P<0.05$ and $P<0.01$. Note the duration-dependent reduction in the number of neurons in the CA3 subfield of the bite-raised mice, but not in that of controls. 
tion is associated with an increase in hippocampal changes ${ }^{10)}$, and that the effects of chronic stress are dependent on the duration of the stress treatment $^{11)}$.

Although the severity of effects increased with duration, the bite-raised condition induced significant changes in the first week following the operation. The effect increased in week 2, and again in week 3 , indicating that the effect of the bite-raised condition on spatial learning and number of hippocampal neurons is time-dependent. Furthermore, the effects of the bite-raised condition on neuron loss and learning ability occurred in parallel.

The findings of the present study suggest that the bite-raised condition facilitates senescenceaccelerated deterioration of spatial memory: (1) learning ability in a water maze decreased with $\operatorname{age}^{7)},(2)$ decreased learning ability due to the biteraised condition was observed in aged mice, but not in young adult mice ${ }^{7)}$, and (3) the extent of this suppressive effect in aged mice was dependent on the duration of the bite-raised condition.

Chronic stress impairs maze learning performance $^{18)}$ and induces hippocampal neuronal degeneration $^{19,20)}$. Exposure to corticosterone causes hippocampal neuronal degeneration and spatial learning deficits ${ }^{21)}$, suggesting that chronic stressinduced maze learning deficits and hippocampal degeneration are mediated by increased plasma corticosterone levels. Moreover, in rats ${ }^{22}$ and SAMP8 mice ${ }^{23)}$, the administration of metyrapone blocks chronic stress-induced neuronal degeneration in hippocampus and chronic stress-induced impairments in spatial learning. Indeed, in our recent study, the bite-raised condition increased plasma corticosterone levels ${ }^{7,9)}$, induced impairments of spatial learning in the Morris water test $^{7,9)}$, increased neuronal death in the hippocampal CA3 subfield ${ }^{7)}$, and pretreatment of aged bite-raised SAMP8 mice with metyrapone prevented hippcampal neuron loss and spatial memory deficits ${ }^{9)}$. These data strongly suggest that the behavioral and morphological deficits induced by raising the bite in aged SAMP8 mice are results of increased plasma corticosterone levels. In conclusion, in aged bite-raised SAMP8 mice, hippocampal neuron loss and spatial memory deficits were closely related to the duration of the biteraised condition.

\section{Acknowledgement}

This work was supported in part by Grant-in Aid for Scientific Research from the Ministry of Education, Science and Culture of Japan (16592058).

\section{References}

1) Umemoto G. The treatment of three patients who insist that indefinite complaints arise from occlusion. Jap J Psychosomatic Dent 1998; 13:133-139. (in Japanese)

2) Christensen J. Effect of occlusal-raising procedures on the chewing system. Dent Proct Dent Res 1970; 20:233-238.

3) Hada $\mathbf{N}$ and Mushimoto E. Relationship between occlusal interference position and localizing EEG potential per hemisphere. Dent J Iwate Med Univ 2005; 30:32-41. (in Japanese)

4) Toyoda $Y$ and Mushimoto E. Location of electric current sources with activation of experimental occlusal interference in the human brain by dipole tracing method. J Jpn Prosthodont Soc 2004; 48:183-192. (in Japanese)

5) Yoshihara $T$, Matsumoto $Y$ and Ogura T. Occlusal disharmony affects plasma corticosterone and hypothalamic noradrenalin release in rats. J Dent Res 2001; 80:2089-2092.

6) Areso MP, Giralt MT, Sainz B, Prieto M, Garcīa-Vallejo P and Gōmez FM. Occlusal disharmonies modulate central catecholaminergic activity in the rat. J Dent Res 1999; 78:1204-1213.

7) Kubo K, Yamada Y, Iinuma M, Iwaku F, Tamura Y, Watanabe K, Nakamura H and Onozuka M. Occlusal disharmony induces spatial memory impairment and hippocampal neuron degeneration via stress in SAMP8 mice. Neurosci Letters 2007; 414:188-191.

8) Krugers HJ, Maslam S, Korf J and Joëls M. The corticosterone synthesis inhibitor metyrapone prevents hypoxia/ ischemia-induced loss of synaptic function in the rat hippocampus. Stroke 1998; 2:237-249.

9) Kubo K, Iwaku F, Arakawa Y, Ichihashi Y, Iinuma M, Tamura Y, Karasawa N, Nagatsu I, Sasaguri K and Onozuka M. The corticosterone synthesis inhibitor metyrapone prevents bite-raising induced impairment of hippocampal function in aged senescence-accelerated prone mice (SAMP8). Biogenic Amines 2007. (in press)

10) Onozuka M, Watanabe K, Mirbord SM, Ozono S, Nishiyama K, Karasawa N and Nagatsu I. Reduced mastication stimulates impairment of spatial memory and degeneration of hippocampal neurons in aged SAMP8. Brain Res 1999; 826:148-153.

11) Sakaguchi $T$ and Nakamura $S$. Duration-dependent effects of repeated restraint stress on cortical projections of locus coeruleus neurons. Neurosci Lett 1990; 118:193-196.

12) Flood JF and Morley JE. Learning and memory in the SAMP8 mouse. Neurosci Biobehav Rev 1998; 22:1-20.

13) Hosokawa M, Abe T, Higuchi K, Shimakawa K, Omor $Y$, Matsushita T, Kogishi K, Deguchi E, Kishimoto Y, Yasuoka $\mathrm{K}$ and Takeda T. Management and design of the maintenance of SAM mouse strains: an animal model for accelerated senescence and age-associated disorders. Exp Gerontol 1997; 32:111-116.

14) Morris RGM. Development of a water-maze procedure for studing spatial learning in the rat. J Neurosci Methods 1984; 11:47-60.

15) Skelton RW and Mc Namara PK. Bilateral knife cuts to the perforant path disrupt spatial learning in the Morris water maze. Hippocampus 1992; 2:73-80.

16) Desjardins S, Mayo W, Vallēe M, Hancock D, Moal LE, Simon $\mathrm{H}$ and Abrous DN. Effect of aging on the basal expression of c-Fos, c-Jun, and Egr-1 prpteins in the hippocampus. Neurobiol Aging 1997; 18:37-44.

17) Flanklin KB and Paxinos J. The mouse brain in stereotaxic coordinates, Academic Press, New York, USA 1996; 1313.

18) Luine V, Villegas M, Martinez $C$ and McEwen BS. Re- 
peated stress causes reversible impairment of spatial memory performance. Brain Res 1994; 639:167-170.

19) Watanabe $Y$, Gould $E$ and McEwen BS. Stress induces atrophy of apical dendrites of hippocampal CA3 pyramidal neurons. Brain Res 1992; 588:341-345.

20) Conrad CD, LeDoux JE, Magarińos AM and McEwen BS. Repeated restraint stress facilitates fear conditioning independently of causing hippocampal CA3 dendritic atrophy. Behav Neurosci 1999; 113:902-913.

21) Sapolsky RM, Krey LC and McEwen BS. Prolonged glu- cocorticoid exposure reduces hippocampal neuron number implications for aging. J Neurosci 1985; 5:1221-1226.

22) Wright RL, Lightner EN, Harman JS, Meijer OC and Conrad CD. Attenuating corticosterone levels on the day of memory assessment prevents chronic stress-induced impairments in spatial memory. Eur J Neurosci 2006; 24:595606.

23) Onozuka M, Watanabe K, Fujita M, Tonosaki K and Saito $\mathrm{S}$. Evidence for involvement of glucocorticoid response in the hippocampal change in aged molarlsess SAMP8 mice. Behav Brain Res 2002; 131:125-129. 
